\title{
Isolation of Campylobacters from Intestinal Tract of Poultry in Northern Region of India
}

\author{
Chetana Vaishnavi*, Meenakshi Singh, Prashant Kapoor \\ Department of Gastroenterology Postgraduate, Institute of Medical Education and Research, Chandigarh, India \\ Email: "c.vaishnavi@rediffmail.com
}

Received 16 October 2015; accepted 13 November 2015; published 16 November 2015

Copyright (C) 2015 by authors and Scientific Research Publishing Inc.

This work is licensed under the Creative Commons Attribution International License (CC BY). http://creativecommons.org/licenses/by/4.0/

(c) (i) Open Access

\begin{abstract}
Campylobacter is one of the most common food-borne bacterial enteropathogens. We planned to investigate the prevalence and antibiotic resistogram of Campylobacter in poultry in and around Chandigarh. Poultry samples $(n=127)$ were obtained from slaughter houses/retail outlets and cultured microaerophilically on Campylobacter media. The isolates were identified phenotypically and by molecular investigation. Identification of specific genes to look for resistance to nalidixic acid, ciprofloxacin, tetracyclin and streptomycin was also done. Campylobacter was isolated from $57 / 127(44.9 \%)$ of the samples. The most frequent serotypes identified were $B: 2, S: 27, Z_{5}: 52$ and $\mathrm{Z}_{7}$ : 57 . All culture isolates $(100 \%)$ were reconfirmed as Campylobacter by $16 \mathrm{~S}$ rRNA polymerase chain reaction. Molecular identification of isolates revealed the presence of $C$. jejuni in $45(79.0 \%)$, $C$. coli in 1 (1.8\%) and co-infection of $C$. coli and $C$. jejuni in 11 (19.3\%). No $C$. lari and $C$. upsaliensis were detected. Antibiogram typing showed nalidixic acid resistance in $36.8 \%$, ciprofloxacin resistance in $35.0 \%$ and $31.5 \%$ resistance for both streptomycin and tetracyclin. A high level of Campylobacter prevalence was found among the poultry with $C$. jejuni being the most commonly isolated species. Resistance to major antibiotics among Campylobacter isolates from poultry was also very high. The study of prevalence of Campylobacter in poultry and its resistance to major antibiotics will help to plan risk burden strategies throughout the food chain.
\end{abstract}

\section{Keywords}

Antibiotic Resistance, Campylobacter, Molecular Investigation, Phenotypic Identification, Poultry, Serotyping

\section{Introduction}

Campylobacter has long been known as a part of the normal flora in the intestine of most animals including poultry due to their high body temperature which provides an optimum growth milieu for this thermotolerant

*Corresponding author. 
genus [1]. The organism has been found to be responsible for causing abortion in cattle and sheep and diarrhea in cattle and pigs [2]. Human beings can acquire Campylobacter through consumption of raw or undercooked meat and poultry [3], contaminated water and vegetables [4], unpasteurized milk [5], or by contact with fecal matter from infected domestic pets or people [6]. As poultry meat is a good source of animal protein, it is easily appealing to consumers and the consumption of which leads to infections. Poultry is therefore considered to be the main reservoir for campylobacteriosis in humans. Poultry meat is of prime importance in food associated disease in developed countries [7]. The most common Campylobacters causing human diseases are C. jejuni and C. coli with rarely other species like C. fetus, C. upsaliensis and C. lari [8] [9]. C. jejuni has been reported to be the most commonly isolated species in chickens [1]. Thus, Campylobacter is one of the most common agents of bacterial gastroenteritis and a major health burden for both developed and developing countries [10].

Campylobacter is an important bacterial cause of food-borne disease outbreaks in the United States [11]. Studies on antibiotic resistant pattern of Campylobacters from developing countries are sparse, due to lack of funding and facilities for culture. There is a paucity of information from India regarding Campylobacter and their antibiotic resistance pattern in poultry, probably due to the absence of surveillance in our region. Campylobacter infections remain a high research priority for improvement of strategies related to prevention and management of the disease [9]. As poultry is the main reservoir of Campylobacters for human transmission, there is clearly a need for local surveillance and control measures based on quantitative data of Campylobacter colonization in poultry. The present work was carried out to study the prevalent antibiotic profile of Campylobacters isolated from poultry in Chandigarh, a northern region of India.

\section{Materials and Methods}

The study was approved by the Institute Ethics Committee of Post Graduate Institute of Medical Institute and Research, Chandigarh, India and was conducted from May 2009 to January 2013.

\subsection{Poultry Sample Collection}

One hundred and twenty seven poultry samples from slaughter houses/retail outlets in and around Chandigarh formed the basis of investigation. Lower intestinal portions of poultry were collected in campy-thioglycollate media (HiMedia, India), transported in an ice bucket to the Microbiology Division of the Department of Gastroenterology and were immediately processed for the isolation of Campylobacters. This was the same time period (May 2009 and January 2013) and geographical area (Mauli Jagran and Indira colony) from where the community fecal samples investigating for Campylobacters were collected in an earlier study [9].

\subsection{Culture for Campylobacters}

Poultry intestine pieces were homogenized in physiological saline and vortex mixed for 1 min under sterile conditions. The suspension was inoculated directly either on selective Campylobacter agar base media (Oxoid Ltd., Cheshire, England) containing antibiotics and 5\% - 7\% defibrinated sheep blood oron charcoal cefoperazone deoxycholate agar (Oxoid Ltd., Cheshire, England) by quadrant streaking. The suspensions were also passed through filter membrane of pore size $0.45 \mu \mathrm{m}$ and $0.65 \mu \mathrm{m}$ (Millipore, USA) placed on media plates and kept as such for one hour. The filters were then removed and discarded. All the plates were incubated under microaerophilic conditions at $37^{\circ} \mathrm{C}$ and $42^{\circ} \mathrm{C}$ for $72 \mathrm{~h}$.

\subsection{Phenotypic Identification of Campylobacters}

Predominant or pure growth of grey to ceramic colonies (Figure 1) was investigated by Gram stain and by biochemical tests viz. catalase, oxidase and hippurate hydrolysis. Campylobacter species was suspected when the isolate gave positive reaction with oxidase and/or hippurate (Figure 2) in addition to any other positive identification tests.

\subsection{Serotyping of $C$. jejuni}

The pathogenic C. jejuni was serotyped on the basis of its heat stable "O" antigen extract and a passive hemag- 


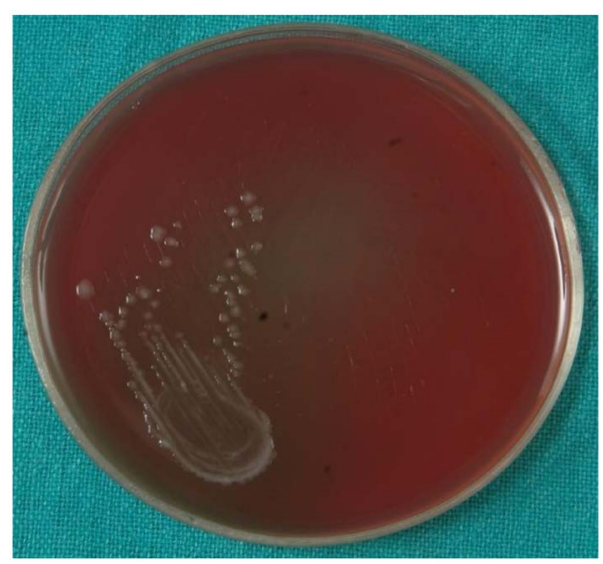

Figure 1. Colonies of Campylobacter on Campylobacter agar base media.

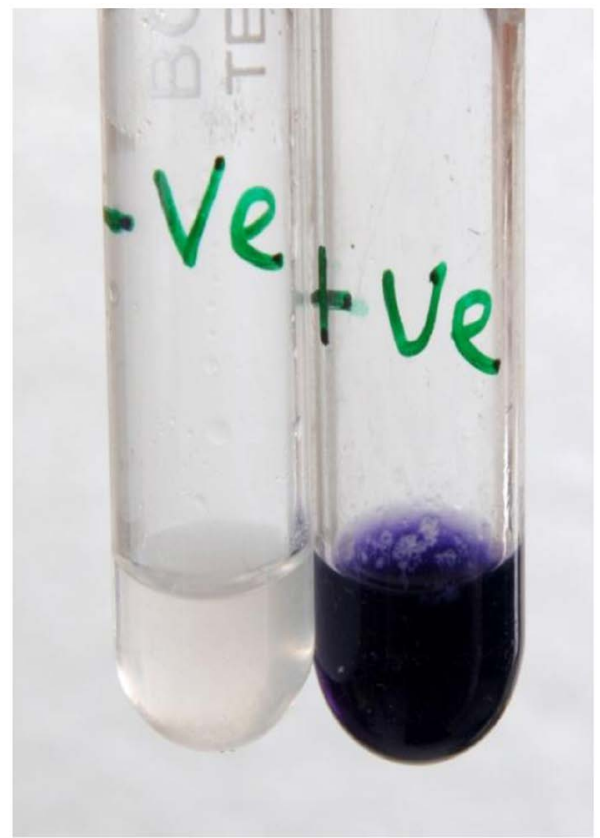

Figure 2. Formation of purple color indicative of positive hippurate hydrolysis.

glutination assay using 25 C. jejuni specific antisera (Denka-Seiken, Japan). For this procedure, antigen was prepared by suspending a loopful of the organisms in physiological saline, heating at $100^{\circ} \mathrm{C}$ for $1 \mathrm{~h}$ and centrifuging at $3287 \mathrm{~g}$ for 5 mins. The extracted antigen was suspended in $500 \mu \mathrm{l}$ phosphate buffered saline. This suspension was mixed with an equal volume of washed suspension of sheep erythrocytes $(1 \% \mathrm{v} / \mathrm{v})$. After sensitization for 1 hour at $37^{\circ} \mathrm{C}$, erythrocytes were washed and resuspended to $500 \mu \mathrm{l}$. Twenty-five microliter each of 25 antisera were added in U-bottom microplates and an equal volume of sensitized sheep erythrocyte suspension was added to each well. The plates were observed for agglutination after incubation at $37^{\circ} \mathrm{C}$ for 30 mins.

\subsection{Molecular Identification of Campylobacter Isolates}

Campylobacter isolates were subjected to molecular identification for different species by polymerase chain reaction (PCR). For isolation of DNA, heavy growth of Campylobacter isolate was suspended in $500 \mu \mathrm{l}$ TrisEDTA buffer. The suspension was boiled at $100^{\circ} \mathrm{C}$ for 10 mins and immediately transferred to an ice bath and incubated for $1 \mathrm{~h}$. Next, the suspension was centrifuged at $6710 \mathrm{~g}$ for 2 mins and the supernatant was separated and 
checked for DNA by $0.8 \%$ agarose gel electrophoresis. The primers (Table 1) used to identify Campylobacter species and antibiotic resistance by amplifying specific genes are the same as those mentioned in an earlier publication [9]. All the PCR products were analyzed by electrophoresis on $1.8 \%$ agarose gel containing $0.1 \mu \mathrm{g} / \mathrm{ml}$ ethidium bromide.

(1) Identification of Campylobacter species: PCR assay was done using specific primers to the unique regions of Campylobacter genus and to the unique regions of different Campylobacter species. Species-specific identification of C. jejuni, C. coli, C. lari and C. upsaliensis was done by amplifying the hippuricase (hipO) gene, the aspartokinase (aspK) gene, the serine hydroxymethyl transferase (glyA) gene and lipopolysaccharide (lpxA) gene respectively.

(2) Detection of antibiotic resistance: Nalidixic acid resistance was identified by amplifying specific gyrA gene using primers gyrA forward and gyrA reverse. Ciprofloxacin (gyrA) resistance gene in Campylobacter isolates was investigated by Mismatch Amplification Mutation Assay (MAMA) using a conserved forward primer, Campy MAMA gyrA1 and a mutation detection reverse primer, Campy MAMA gyrA5. An annealing temperature of $50^{\circ} \mathrm{C}$ was used to give $265 \mathrm{bp}$ products which indicated the presence of the Thr-6 to Ile (ACA $\rightarrow$ ATA) mutation in the Campylobacter gyrA gene. Tetracyclin resistance was detected by using specific primers to amplify tetO gene. Streptomycin resistance was detected by amplifying the strA gene.

\section{Results}

\subsection{Phenotypic Methods}

Campylobacter was isolated from 57/127 (44.9\%) of the poultry samples by culture. Eighteen (31\%) of the C. jejuni isolates were serotyped. The serotype of the tested organism was determined as positive based on agglutination obtained over the bottom of well and as negative when button formation occurred (Figure 3). If the organism reacted to multiple antisera, it was determined as multiple serotypes. The most frequent serotypes of $C$. difficile from poultry isolates in descending order were $\mathrm{B}: 2, \mathrm{~S}: 27, \mathrm{Z}_{5}: 52, \mathrm{~V}: 32$ and $\mathrm{Z}_{7}: 57$ (Table 2).

\subsection{Molecular Methods}

All the 57 (100\%) culture positive isolates were reconfirmed as Campylobacter species by molecular investigation for 16S rRNA, hipO, aspK, glyA and lpxA genes. PCR revealed the presence of C. jejuni in 45 (79.0\%), C. coli in $1(1.8 \%)$ and co-infection of $C$. coli and C. jejuni in $11(19.3 \%)$ of the cultures but were negative for $C$. lari and $C$. upsaliensis. Antibiogram typing done by molecular methods showed nalidixic acid resistance in $36.8 \%$ (21/57), ciprofloxacin resistance in 35.0\% (20/57) and 31.5\% (18/57) resistance each for streptomycin and tetracycline (Figure 4).

Table 1. Primers used for amplification of target genes of Campylobacter.

\begin{tabular}{|c|c|c|c|}
\hline S. No. & Target genes & Primer Sequences & References \\
\hline 1 & $16 \mathrm{~S}$ rRNA & $\begin{array}{l}\text { F-5’ AATCTAATGGCTTAACCATTA 3’ } \\
\text { R-5’ GTAACTAGTTTAGTATTCCGC 3' }\end{array}$ & Linton et al. [32] \\
\hline 2 & hipO (C. jejuni) & $\begin{array}{c}\text { F-5’ GGAGAGGGTTTGGGTGGT-3’ } \\
\text { R-5'-AGCTAGCCTCGCATAATAACTTG-3’ }\end{array}$ & Linton et al. [32] \\
\hline 3 & $\operatorname{aspK}($ C. coli) & $\begin{array}{l}\text { F-5’ GGTATGATTTCTACAAAGCGAG-3’ } \\
\text { R-5’ATAAAAGACTATCGTCGCGTG-3’ }\end{array}$ & On and Jordan [33] \\
\hline 4 & glyA (C. lari) & $\begin{array}{l}\text { F-5’ TAGAGAGATAGCAAAAGAGA 3’ } \\
\text { R-5’ TACACATAATAATCCCACCC 3’ }\end{array}$ & Yamazaki-Matsune et al. [34] \\
\hline 5 & lpxA (C. upsaliensis) & $\begin{array}{l}\text { F-5’CGATGATGTCAAATTGAAGC 3’} \\
\text { R-5’ TTCTAGCCCCTTGCTTGATG 3’ }\end{array}$ & Yamazaki-Matsune et al. [34] \\
\hline 6 & Tetracyclin (tetO) & 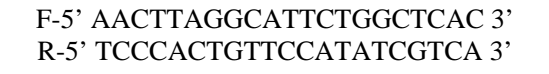 & Ng et al. [35] \\
\hline 7 & Nalidixic acid (gyrA) & $\begin{array}{l}\text { F-5’ GCT CTT GTT TTA GCT TGATGCA 3’ } \\
\text { R-5’ TTG TCG CCA TC CTA CAGCTA 3’ }\end{array}$ & Jesse et al. [36] \\
\hline 8 & Ciprofloxacin (MAMA gyrA) & $\begin{array}{l}\text { F-5’ TTT TTA GCA AAG ATT CTG AT 3’ } \\
\text { R-5’ CAA AGC ATC ATA AAC TGC AA 3' }\end{array}$ & Zirnstein et al. [37] \\
\hline 9 & Streptomycin (strA) & $\begin{array}{l}\text { F-5’ CCAATCGCAGATAGAAGGCAAG 3' } \\
\text { R-5’ ATCAACTGGCAGGAGGAACAGG 3' }\end{array}$ & Maidhof et al. [38] \\
\hline
\end{tabular}




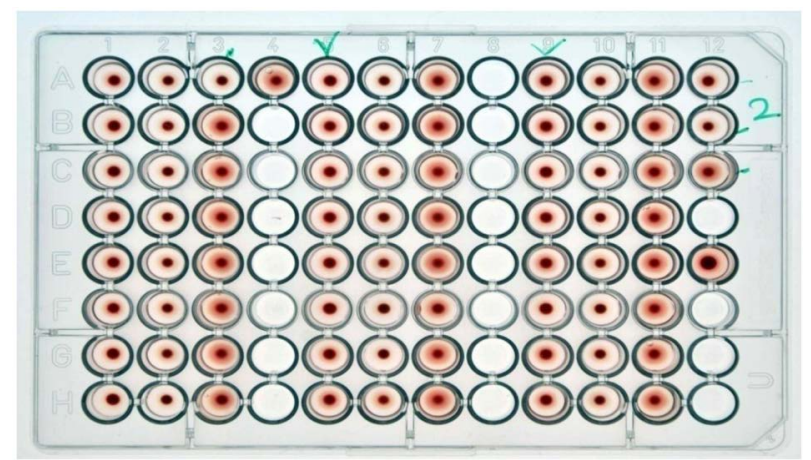

Figure 3. Microplate showing agglutination and button formation for C. jejuni isolates.

Table 2. Number of $C$. jejuni isolates showing multiple serotypes (serotypes are given in alphabetic order and the most frequent ones are marked in bold).

\begin{tabular}{|c|c|}
\hline Serogroup & No. of $C$. jejuni isolates (multiple serotypes) \\
\hline Group A: 1, 44 & 3 \\
\hline Group B: 2 & 19 \\
\hline Group C: 3 & 6 \\
\hline Group D: 4, 13, 16, 43, 50 & 6 \\
\hline Group E: 5 & 3 \\
\hline Group F: 6, 7 & 6 \\
\hline Group G: 8 & 4 \\
\hline Group I: 10 & 6 \\
\hline Group J: 11 & 7 \\
\hline Group K: 12 & 6 \\
\hline Group L: 15 & 7 \\
\hline Group N: 18 & 6 \\
\hline Group O: 19 & 6 \\
\hline Group P: 21 & 5 \\
\hline Group R: 23, 36, 53 & 6 \\
\hline Group S: 27 & 12 \\
\hline Group U: 31 & 6 \\
\hline Group V: 32 & 9 \\
\hline Group Y: 37 & 5 \\
\hline Group Z: 38 & 4 \\
\hline Group $\mathrm{Z}_{2}: 41$ & 7 \\
\hline Group $\mathrm{Z}_{4}: 45$ & 7 \\
\hline Group Z $Z_{5}: 52$ & 12 \\
\hline Group $\mathrm{Z}_{6}: 55$ & 6 \\
\hline Group $Z_{7}: 57$ & 9 \\
\hline
\end{tabular}




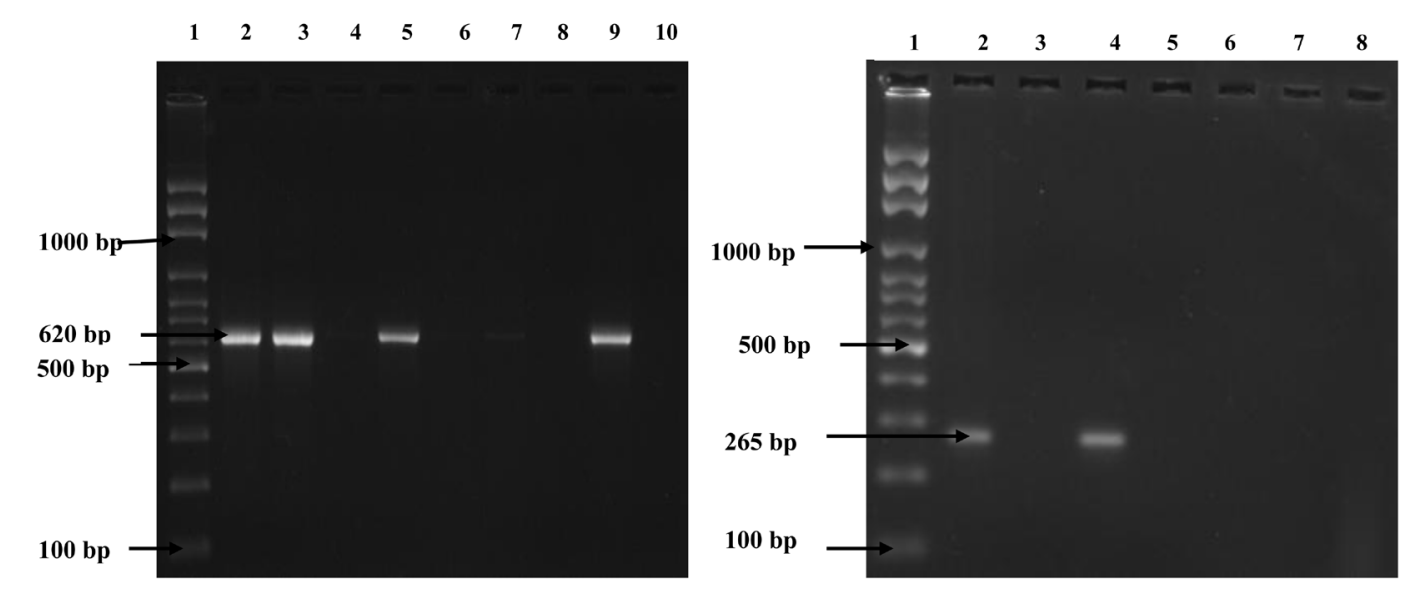

Figure 4. PCR detection of gyrA genes for resistance of nalidixic acid (620 bp) and ciprofloxacin (265 bp) respectively. Lane 1-Marker; Lane 2-Positive control; Lanes 3 to 10-Campylobacter isolates.

\section{Discussion}

Campylobacter is a major health burden for both developed and developing countries. Most of the Campylobacter isolates causing human gastroenteritis are thermo-tolerant variety and can grow even at incubation temperatures of $42^{\circ} \mathrm{C}$. Farm animals and wild birds are the primary sources contributing to human infections of Campylobacter due to consumption of contaminated water. Drinking water gets contaminated from septic seepage and waste water intrusion into ground water sources. Handling and eating undercooked poultry have consistently been shown to be important risk factors in food-borne illness due to Campylobacter [3]. A survey of raw poultry demonstrated that $50 \%-70 \%$ of raw chickens tested at the retail level were contaminated with Campylobacter [12].

C. jejuni has been reported to be the most isolated species in chicken [1]. Yu et al. [13] reported the first recognized major $C$. jejuni outbreak in a middle School in Incheon, associated with contaminated chicken in Korea where an attack rate of $11.6 \%$ occurred with $40.3 \%$ stool samples positive for $C$. jejuni. The authors state that the raw chickens used in the chicken soup with ginseng were supplied frozen $\left(-6^{\circ} \mathrm{C}\right)$ in the morning of July 1 by a company which was free of food hygiene violations. The chickens had been slaughtered and processed on June 29 and were deemed acceptable for use until July 9 under refrigeration. Despite this, the chicken soup prepared and consumed on July 1, 2009 was considered to be the source of human infection [13]. Yano et al. [14] monitored C. jejuni in four chicken farms during the period 2003 to 2006 to elucidate the mechanisms of transmission. A total of 206 C. jejuni isolates were obtained with $C$. jejuni coming from common sources external to the farms. In the present study, prevalence of Campylobacters was $44.9 \%$ in the poultry in and around Chandigarh region and C. jejuni was the most prevalent Campylobacter. This is in contrast to another study from the same region carried out during the same time period among human beings where a low prevalence of Campylobacter was seen [9].

Typing methods have a significant role in the identification, monitoring, and prevention of Campylobacter infections. Combination of phenotypic and genotypic methods can improve species discrimination of pathogens such as Campylobacter. A genotyping method like PCR has been found to be an efficient and reliable typing method with greater discriminatory power providing superior results [15]. Lawson et al. [16] used genetic targets aspK and hipO and Bang et al. [17] used 16S rRNA to identify C. coli and C. jejuni. The same molecular methods were also used in the present study.

Serotyping methods can be used to differentiate clonally related isolates from unrelated ones due to different characteristics. Penner hemaglutination assay is a serotyping method widely used for characterizing Campylobacter isolates. The $C$. jejuni capsular polysaccharides (CPS) are the primary serodeterminant of the Penner scheme. On and off CPS expression by C. jejuni suggests that this tactic might have a role in Campylobacter virulence [18]. Based on their geographic locations, the serotype prevalence of Campylobacter differs across countries. The most predominant serotypes in Japan are B, D, and L, while those in Denmark are serotypes B, A, and D [19] [20]. Ishihara et al. [21] identified 18 serotypes among the C. jejuni isolates from humans with major 
ones being B, D and R. In another study from Thailand [22], C. jejuni isolates from poultry were classified into 10 Penner serotypes viz. A, C, I, K, B, E, S, D, L and R. The most frequent serotypes in the present study were B: 2, S: 27, $Z_{5}: 52$ and $Z_{7}: 57$ in descending order. Thus serotype $B$ seems to be more common among the Campylobacter isolates as also seen in our earlier study in humans [9] and Campylobacter from poultry could be the source of infection among the human population studied from the same region [9].

Another problem of great concern at global level is the acquisition of resistance to multiple antibiotics by Campylobacters due to unregulated use of antimicrobial agents in food animal production [23]. Several resistance genes underlie the emergence of multidrug-resistant Campylobacter. Macrolides and fluroquinolones are commonly prescribed for campylobacteriosis. But, resistance to these and other antibiotics also occurs. In Netherlands almost 30\% of Campylobacter isolates were resistant to fluroquinolones [24]. An increase in fluroquinolone resistance in Campylobacter spp. from Europe and USA has also been reported [25] due to their use in food animals [26]. Since erythromycin is the drug of choice for the treatment of Campylobacter infections the prevalence of resistance to this antimicrobial, especially among strains isolated from food, is a cause of concern. Previous studies on the susceptibility of Campylobacter to macrolides showed that the rate of resistant isolates was at a low level and did not exceed 1\% [27]-[29]. However, a relatively high level of resistance to streptomycin (22.8\%) was reported in Poland [30]. In the present study antibiotic resistance was $36.8 \%$ for nalidixic acid, $35.0 \%$ for ciprofloxacin, and $31.5 \%$ for both streptomycin and tetracyclin. The findings of the present investigation are consistent with previous results as a relatively high level of resistance to streptomycin was seen. Isolates from chicken broilers were 67\% resistant to tetracyclin [31]. The MAMA PCR has been considered as a valuable and reliable alternative technique to sequencing for detection of the Thr-86 $\rightarrow$ Ile mutation for ciprofloxacin [31].

\section{Conclusion}

This study indicates that in northern region of India, there is an increasing emergence of antibiotic resistance among Campylobacter strains in poultry. It is important to reduce the contamination rates by Campylobacter in poultry by planning risk burden strategies throughout the food chain. One limitation of the present study is that we cannot investigate Campylobacters in domestic poultry rearing, which can also be a source of infection to human beings. New strategies for containing Campylobacter infections will likely include limiting consumption of antibiotics by animals, disinfection of their food and water, treatment of their manure, and isolation of the contagiously ill. Other strategies like irradiation of foods of animal origin may become a feasible method of control of the bacterial contamination of foods. Integrated efforts must be done in order to encourage the appropriate use of antimicrobials in food animals and for the implementation of a surveillance system of drug resistance in Campylobacters.

\section{Acknowledgements}

The authors are grateful to Prof. Rama Chaudhry for providing DNA material of C. upsaliensis and C. lari as controls. Mr. Prashant Kapoor and Mr. Vikram Singh are acknowledged for their technical support.

\section{Funding}

This work was supported by the Indian Council of Medical Research, New Delhi.

\section{Transparency Declaration}

There is no conflict of interest.

\section{References}

[1] Noormohamed, A. and Fakhr, M.K. (2014) Molecular typing of Campylobacter jejuni and Campylobacter coli Isolated from Various Retail Meats by MLST and PFGE. Foods, 3, 82-93. http://dx.doi.org/10.3390/foods3010082

[2] Penner, J. (1988) The Genus Campylobacter: A Decade of Progress. Clinical Microbiology Reviews, 1, 157-172.

[3] Little, C.L., Richardson, J.F., Owen, R.J., De Pinna, E. and Threlfall, E.J. (2008) Campylobacter and Salmonella in Raw Red Meats in the United Kingdom: Prevalence, Characterization, and Antimicrobial Resistance Pattern, 2003-2005. Food Microbiol, 25, 538-543. http://dx.doi.org/10.1016/j.fm.2008.01.001 
[4] Evans, M.R., Ribeiro, C.D. and Salmon, R.L. (2003) Hazards of Healthy Living: Bottled Water and Salad Vegetables as Risk Factors for Campylobacter Infection. Emerging Infectious Diseases, 9, 1219-1225. http://dx.doi.org/10.3201/eid0910.020823

[5] Heuvelink, A.E., van Heerwaarden, C., Zwartkruis-Nahuis, A., Tilburg, J.J.H.C., Bos, M.H., Heilmann, F.G., Hofhuis, A., Hoekstra, T. and de Boer, E. (2009) Two Outbreaks of Campylobacteriosis Associated with the Consumption of Raw Cows’ Milk. International Journal of Food Microbiology, 134, 70-74. http://dx.doi.org/10.1016/j.ijfoodmicro.2008.12.026

[6] Luechtefeld, N.W and Wang, W.L.L. (1982) Animal Reservoirs of Campylobacter jejuni. In: Newell, D.G., Ed., Campylobacter: Epidemiology, Pathogenesis, and Biochemistry, MTP Press Limited, Lancaster, 249-252.

[7] Sams, A.R. (2001) Poultry Meat. In: Poultry Meat Processing and Quality, Taylor \& Francis, CRC Press, New York, $395 \mathrm{p}$.

[8] Leatherbarrow, A.J., Hart, C.A., Kemp, R., Williams, N.J., Ridley, A., Sharma, M., Diggle, P.J., Wright, E.J., Sutherst, J. and French, N.P. (2004) Genotypic and Antibiotic Susceptibility Characteristics of a Campylobacter coli Population Isolated from Dairy Farmland in the United Kingdom. Applied and Environmental Microbiology, 70, 822-830. http://dx.doi.org/10.1128/AEM.70.2.822-830.2004

[9] Vaishnavi, C., Singh, M., Thakur, J.S. and Thapa, B.R. (2015) Low Prevalence of campylobacteriosis in the Northern Region of India. Advance in Microbiology, 5, 155-165. http://dx.doi.org/10.4236/aim.2015.53015

[10] Abd El-Baky, R.M., Sakhy, M. and Gad, G.F.M. (2014) Antibiotic Susceptibility Pattern and Genotyping of Campylobacter Species Isolated from Children Suffering from Gastroenteritis. Indian Journal of Medical Microbiology, 32, 240-246. http://dx.doi.org/10.4103/0255-0857.136550

[11] Centers for Disease Control (CDC) (2011) CDC Estimates of Foodborne Illness in the United Sates. http://www.cdc.gov/foodborneburden/2011-foodborne-estimates.html

[12] Danis, K.D., Renzi, M., O’Neill, W., Smyth, B., McKeown, P., Foley, B., Tohani, V. and Devine, M. (2009) Risk Factors for Sporadic Campylobacter Infection: An All-Ireland Case-Control Study. Euro Surveillance, 14, Article ID: 19123.

[13] Yu, J.H., Kim, N.Y., Cho, N.G., Kim, J.H., Kang, Y.A. and Lee, H.G. (2010) Epidemiology of Campylobacter jejuni Outbreak in a Middle School in Incheon, Korea. Journal of Korean Medical Science, 25, 1595-1600. http://dx.doi.org/10.3346/jkms.2010.25.11.1595

[14] Yano, S., Kira, T., Morishita, Y., Ishihara, K., Asai, T., Iwata, T., Akiba, M. and Murase, T. (2013) Colonization of Chicken Flocks by Campylobacter jejuni in Multiple Farms in Japan. Poultry Science, 92, 375-381. http://dx.doi.org/10.3382/ps.2012-02710

[15] Zaidi, M.B., Campos, F.D., Estrada-García, T., Gutierrez, F., León, M., Chim, R. and Calva J.J. (2012) Burden and Transmission of Zoonotic Foodborne Disease in a Rural Community in Mexico. Clinical Infectious Diseases, 55, 51-60. http://dx.doi.org/10.1093/cid/cis300

[16] Lawson, A.J., Shafi, M.S., Pathak, K. and Stanley, J. (1998) Detection of Campylobacter in Gastroenteritis: Comparison of Direct PCR Assay Faecal Samples with Selective Culture. Epidemiology \& Infection, 121, 547-553. http://dx.doi.org/10.1017/S0950268898001630

[17] Bang, D.D., Wedderkopp, A., Pedersen, K. and Madsen, M. (2002) Rapid PCR Using Nested Primers of the 16S rRNA and the Hippuricase (hipO) Genes to Detect Campylobacter jejuni and Campylobacter coli in Environmental Samples. Molecular and Cellular Probes, 16, 359-369. http://dx.doi.org/10.1006/mcpr.2002.0434

[18] Guerry, P., Poly, F., Riddle, M., Maue, A.C., Chen, Y.U. and Monteiro, M.A. (2012) Campylobacter Polysaccharide Capsules: Virulence and Vaccines. Frontiers in Cellular and Infection Microbiology, 2, 7. http://dx.doi.org/10.3389/fcimb.2012.00007

[19] Nielsen, E.M., Engberg, J., Fussing, V., Petersen, L., Brogren, C.H. and On, S.L.W. (2000) Evaluation of Phenotypic and Genotypic Methods for Subtyping of Campylobacter jejuni Isolates from Humans, Poultry, and Cattle. Journal of Clinical Microbiology, 38, 3800-3810.

[20] Saito, S., Yatsuyanagi, J., Harata, S., Ito, Y., Shinagawa, K., Suzuki, N., Amano, K. and Enomoto, K. (2005) Campylobacter jejuni Isolated from Retail Poultry Meat, Bovine Feces and Bile, and Human Diarrheal Samples in Japan: Comparison of Serotypes and Genotypes. FEMS Immunology \& Medical Microbiology, 45, 311-319. http://dx.doi.org/10.1016/j.femsim.2005.05.006

[21] Ishihara, K., Yamamoto, T., Satake, S., Takayama, S., Kubota, S., Negishi, H., Kojima, A., Asai, T., Sawada, T., Takahashi, T. and Tamura, Y. (2006) Comparison of Campylobacter Isolated from Humans and Food-Producing Animals in Japan. Journal of Applied Microbiology, 100, 153-160. http://dx.doi.org/10.1111/j.1365-2672.2005.02769.x

[22] Boonmar, S., Yingsakmongkon, S., Songserm, T., Hanhaboon, P. and Passadurak, W. (2007) Serotypes, Antimicrobial Susceptibility, and gyr A Gene Mutation of Campylobacter jejuni Isolates from Humans and Chickens in Thailand. 
Microbiology and Immunology, 51, 531-537. http://dx.doi.org/10.1111/j.1348-0421.2007.tb03941.x

[23] Parkar, S., Sachdev, D. and Kapadnis, B. (2014) Prevalence and Antibiotic Susceptibility of Thermophilic Campylobacters from Sources Implicated in Horizontal Transmission of Flock Colonization. Indian Journal of Medical Microbiology, 32, 425-429. http://dx.doi.org/10.4103/0255-0857.142259

[24] Jacobs-Reitsma, W.E., Kan, C.A. and Bolder, N.M. (1994) The Induction of Quinolone Resistance in Campylobacter bacteria in Broilers by Quinolone Treatment. Letters in Applied Microbiology, 19, 228-231. http://dx.doi.org/10.1111/j.1472-765x.1994.tb00950.x

[25] Silva, J., Leite, D., Fernandes, M., Mena, C., Gibbs, P.A. and Teixeira, P. (2011) Campylobacter spp. as a Foodborne Pathogen: A Review. Frontiers in Microbiology, 2, 200. http://dx.doi.org/10.3389/fmicb.2011.00200

[26] Kirkpatrick, B.D. and Tribble, D.R. (2011) Update on Human Campylobacter jejuni Infections. Current Opinion in Gastroenterology, 27, 1-7. http://dx.doi.org/10.1097/MOG.0b013e3283413763

[27] Andersen, S.R., Saadbye, P., Shukri, N.M., Rosenquist, H., Nielsen, N.L. and Boel, J. (2006) Antimicrobial Resistance among Campylobacter jejuni Isolated from Raw Poultry Meat at Retail Level in Denmark. International Journal of Food Microbiology, 107, 250-255. http://dx.doi.org/10.1016/j.ijfoodmicro.2005.04.029

[28] Rozynek, E., Dzierzanowska-Fangrat, K., Korsak, D., Konieczny, P., Wardak, S., Szych, J., Jarosz, M. and Dzierzanowska, D. (2008) Comparison of Antimicrobial Resistance of Campylobacter jejuni and Campylobacter coli Isolated from Humans and Chicken Carcasses in Poland. Journal of Food Protection, 71, 602-607.

[29] Wozniak, A. and Wieliczko, A. (2011) Tetracycline, Erythromycin, and Gentamicin Resistance of Campylobacter jejuni and Campylobacter coli Isolated from Poultry in Poland. Bulletin of the Veterinary Institute in Pulawy, 55, 51-54.

[30] Wieczorek, K., Szewczyk, R. and Osek, J. (2012) Prevalence, Antimicrobial Resistance, and Molecular Characterization of Campylobacter jejuni and C. coli Isolated from Retail Raw Meat in Poland. Veterinarni Medicina, 57, $293-299$.

[31] Guevremont, E., Nadeau, E. and Sirois, M. (2006) Antimicrobial Susceptibilities of Thermophilic Campylobacters from Humans, Swine, and Chicken Broilers. Canadian Journal of Veterinary Research, 70, 81-86.

[32] Linton, D., Lawson, A.J., Owen, R.J. and Stanley, J. (1997) PCR Detection, Identification to Species Level, and Fingerprinting of Campylobacter jejuni and Campylobacter coli Direct from Diarrheic Samples. Journal of Clinical Microbiology, 35, 2568-2572.

[33] On, S.L.W. and Jordan, P.J. (2003) Evaluation of 11 PCR Assays for Species-Level Identification of Campylobacter jejuni and Campylobacter coli. Journal of Clinical Microbiology, 41, 330-336. http://dx.doi.org/10.1128/JCM.41.1.330-336.2003

[34] Yamazaki-Matsune, W., Taguchi, M., Seto, K., Kawahara, R., Kawatsu, K., Kumeda, Y., Kitazato, M., Nukina, M., Misawa, N. and Tsukamoto, T. (2007) Development of a Multiplex PCR Assay for Identification of Campylobacter coli, Campylobacter fetus, Campylobacter hyointestinalis subsp. hyointestinalis, Campylobacter jejuni, Campylobacter lari and Campylobacter upsaliensis. Journal of Medical Microbiology, 56, 1467-1473. http://dx.doi.org/10.1099/jmm.0.47363-0

[35] Ng, L.K., Martin, I., Alfa, M. and Mulvey, M. (2001) Multiplex PCR for Detection of Tetracycline Resistant Genes. Molecular and Cellular Probes, 15, 209-215. http://dx.doi.org/10.1006/mcpr.2001.0363

[36] Jesse, T.W., Englen, M.D., Pittenger-Alley, L.G. and Fedorka-Cray, P.J. (2006) Two Distinct Mutations in gyrA Lead to Ciprofloxacin and Nalidixic Acid Resistance in Campylobacter coli and Campylobacter jejuni Isolated from Chickens and Beef Cattle. Journal of Applied Microbiology, 100, 682-688. http://dx.doi.org/10.1111/j.1365-2672.2005.02796.X

[37] Zirnstein, G., Li, Y., Swaminathan, B. and Angulo, F. (1999) Ciprofloxacin Resistance in Campylobacter jejuni Isolates Detection of gyrA Resistance Mutations by Mismatch Amplification Mutation Assay PCR and DNA Sequence Analysis. Journal of Clinical Microbiology, 37, 3276-3280.

[38] Maidhof, H., Guerra, B., Abbas, S., Elsheikha, H.M., Whittam, T.S. and Beutin, L. (2002) A Multiresistant Clone of Shiga Toxin Producing Escherichia coli O118:[H16] Is Spread in Cattle and Humans over Different European Countries. Applied and Environmental Microbiology, 68, 5834-5842. http://dx.doi.org/10.1128/AEM.68.12.5834-5842.2002 


\section{List of Abbreviations}

1) \%-Percentage

2) $\mu g-$ Microgram

3) $\mu \mathrm{l}$-Microliter

4) aspK-aspartokinase

5) C. coli-Campylobacter coli

6) C.fetus-Campylobacter fetus

7) C. jejuni-Campylobacter jejuni

8) C. lari-Campylobacter lari

9) C. upsaliensis-Campylobacter upsaliensis

10) CPS-Capsular polysaccharides

11) DNA-Deoxyribonucleic acid

12) EDTA-Ethylenediaminetetraacetic acid

13) g-gravity

14) glyA-Glycine

15) gyrA-Gyrase A

16) h-hour

17) hip $\mathrm{O}$-hippuricase

18) Ile-Isoleucine

19) IpxA-lipopolysaccharide

20) MAMA-Mismatch Amplification Mutation Assay

21) mins-minutes

22) ${ }^{\circ} \mathrm{C}$-Degrees Celsius

23) PCR-Polymerase chain reaction

24) rRNA-Ribosomal ribonucleic acid

25) strA-streptomycin A gene

26) tet $\mathrm{O}$ - tetracyclin $\mathrm{O}$ gene

27) Thr-Threonine 